\title{
Diagnostic and Management Pathway for Sepsis
}

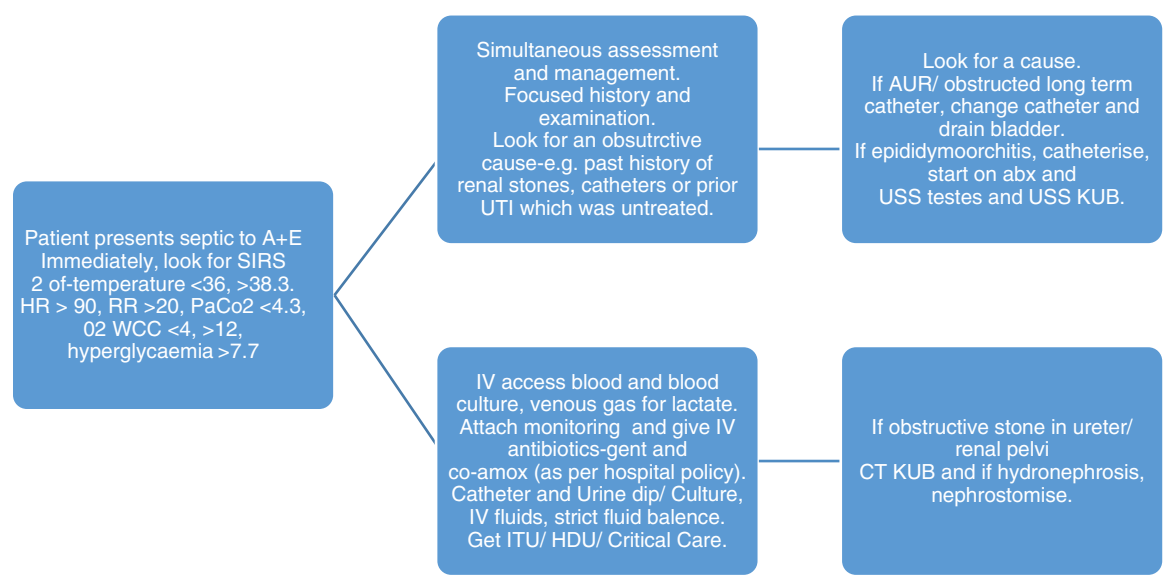

\section{Suggested Reading}

Cawcutt KA, Peters SG. Severe sepsis and septic shock: clinical overview and update on management. Mayo Clin Proc. 2014;89(11):1572-8.

Moore LJ, Moore FA. Early diagnosis and evidence-based care of surgical sepsis. J Intensive Care Med. 2013;28(2):107-17.

Singer M, Deutschman CS, Seymour CW, Shankar-Hari M, Annane D, Bauer M, Bellomo R, Bernard GR, Chiche JD, Coopersmith CM, Hotchkiss RS, Levy MM, Marshall JC, Martin GS, Opal SM, Rubenfeld GD, van der Poll T, Vincent JL, Angus DC. The third international consensus definitions for sepsis and septic shock (Sepsis-3). JAMA. 2016;315(8):801-10. 